\title{
PLURALISMO JURÍDICO, COLONIALIDADADE NORMATIVA E A BUSCA POR NOVAS SUBJETIVIDADES JURÍDICAS
}

\section{${ }^{1}$ Maria Cristina Vidotte Blanco Tarrega}

\section{RESUMO}

Novas subjetividades, no pluralismo jurídico, exigem revisão da colonialidade normativa. Neste artigo, a partir de composição teórica, sugerem-se parâmetros para busca dos sujeitos e das subjetividades que concretizam a insurgência democrática e o pluralismo. $\mathrm{O}$ trabalho se desenvolve a partir da hermenêutica crítica. Resulta da investigação que o locus das subjetividades para realizar o pluralismo jurídico, o seu campo de deveres e atribuições são os espaços público, comunitário e político. O sujeito nesses espaços conhece e interpreta a realidade, respondendo por meio de uma racionalidade emancipatória, que conhece e estende aos outros sujeitos da comunidade, com caráter de empoderamento.

Palavras-chave: Pluralismo jurídico, Colonialidade normativa, Subjetividades jurídicas

\section{PLURALISMO JURÍDICO, COLONIALIDAD NORMATIVA Y LA BUSQUEDA POR NUEVAS SUBJETIVIDADES JURÍDICAS.}

\section{RESUMEN}

Nuevas subjetividades en el pluralismo jurídico requieren revisión de la colonialidad normativa. En este artículo, a partir de la composición teórica se sugieren parámetros para la búsqueda de los sujetos y subjetividades que encarnan insurgencia democrática y el pluralismo. El trabajo se desarrolla desde la hermenéutica crítica. Los resultados son que el lugar de la subjetividad para realizar el pluralismo jurídico son los espacios públicos, comunitarios y políticos. El sujeto conoce y interpreta la realidad en estos espacios y contesta con una racionalidad emancipadora que conoce y se extiende a otras personas de la comunidad, como empoderamiento.

Palabras-claves: Pluralismo jurídico, Colonialidad normativa, Subjetividades jurídicas

\footnotetext{
1 Doutora em Direito pela Pontifícia Universidade Católica de São Paulo - PUC/SP, São Paulo. (Brasil). Professora da Universidade Federal de Goiás - UFG, Goiás. (Brasil). E-mail: mcvidotte@ uol.com.br
} 


\section{INTRODUÇÃO}

A América Latina conhece processos democráticos plurais, originários de movimentos de cunho popular, que se evidenciam, de forma mais ou menos avançada, nas novas Constituições das duas ou três últimas décadas. Estas Cartas Políticas indicam mudanças sociais e políticas importantes, sobretudo na Bolívia, Colômbia e Equador, pautadas no pluralismo epistemológico, político, jurídico, social.

Em sede de pluralismo e no campo das subjetividades e titularidades jurídicas as Cartas latino-americanas garantem, ao menos formalmente, o respeito às diversidades e diferenças, exigindo a superação da colonialidade normativa que impera a partir do conceito de sujeito de direito. Para a produção da normatividade, o direito liberal ocidental moderno criou, individualizou e tornou autônoma a categoria sujeito de direito, conferindo capacidade e tutela àqueles que nela se enquadrassem, à medida do seu potencial de produzir ou fazer circular riquezas. O processo democrático latino-americano exige um alargamento desse conceito, respeitante das pluralidades. É imperioso refletir sobre os sujeitos na perspectiva do pluralismo jurídico, para formar novos quadros teóricos que superem a colonialidade subjetiva, sobretudo para que deem suporte ao exercício da jurisdição.

As constituições latino-americanas introduziram novos titulares de direito. Com a inclusão de certos direitos, foram criadas outras subjetividades como no caso dos direitos da natureza, dos direitos coletivos, sociais, étnicos. Por outro lado, esse novo constitucionalismo exigiu uma refiguração do sujeito de direito ao instituir uma igualdade material complexa, inclusiva do reconhecimento das diferenças, banindo a ideia liberal de igualdade deformadora e opressora. Avançando além da noção de sujeito individual de direito antropocêntrico moderno, emergiram novos sujeitos de direito, sujeitos plurais. Isso se dá pela identificação de sujeitos de direitos em grupos menos protegidos pelo direito liberal contratualista, como mulheres, crianças e jovens, deficientes, idosos. Grupos de sujeitos diferenciados que não eram reconhecidos porque a medida liberal da tutela jurídica é a capacidade de produzir e fazer circular riquezas.

O avanço ocorre também por meio do resgate de sujeitos historicamente esquecidos ou marginalizados, como os povos indígenas, os quilombolas.

Resgatar os sujeitos ocultados, coletivos é recontextualizá-los, acolhendo-os na sua historicidade, territorialidade, na sua cultura. Impõe-se reconhecê-los comunitária, coletiva e politicamente. É mister a perspectiva plural, para os direitos e 
para o poder.

Os objetivos do presente trabalho são discutir critérios, possibilidades e fundamentos teóricos e filosóficos para revisão da colonialidade normativa, dos conceitos e categorias no campo dos sujeitos de direito, na perspectiva do pluralismo jurídico.

Pretende-se, ainda, a partir de uma composição teórica dos estudos postos pelos referenciais eleitos, sugerir parâmetros para a busca dos sujeitos e das subjetividades que concretizam essa insurgência democrática.

Por outro lado, o processo democrático impõe o pluralismo político o que convoca o pluralismo jurídico. Todo sujeito, ao contrário do sujeito de direito liberal apolítico, é um sujeito político, amparado no seu contexto comunitário, cultural, exigindo uma reflexão sobre o pluralismo jurídico, suas bases teóricas e seu uso no direito contemporâneo.

No plano teórico, o pluralismo jurídico é diverso e complexo, porém, nas suas diferentes formações tem servido de fundamento a novas propostas de normatividade e legitimação do direitos emergentes das Cartas Políticas. Dá sustentação para a emancipação dos sujeitos de direito, superando o modelo impresso pela modernidade, caracterizado pelas ideias de uniformização, homogeneização, normalização, universalização, abstração e negação sistemática da diversidade de todos os aspectos da vida.

Nesta temática desenvolve-se o presente trabalho, numa perspectiva teórico metodológica da hermenêutica crítica, tendo por principais referências o ensaio ricoeuriano sobre o sujeito de direito, a subjetividade em Bubber, a formação histórica dos conceitos em Reis Marques e Paolo Grossi e o pluralismo jurídico em Wolkmer e Correas. Os processos constituintes são lidos a partir de Zaffaroni, Garapon e Quadros Magalhães.

\section{PLURALISMOS JURÍDICOS NOS PROCESSOS DEMOCRÁTICOS.}

O pluralismo jurídico contemporâneo, no Eixo Sul, passa pelos processos constituintes que se iniciam com as Cartas dos anos oitentas, com a abertura à maior participação popular, continuando nos anos noventas com ampliação da igualdade pública e da participação democrática nos processos decisórios e se firmando nos na primeira década dos anos dois mil, com uma ampliação das subjetividades políticas e jurídicas, consagrando delineamentos de sociedades plurais.

Os processos constituintes latino-americanos, a partir da década de 1980, com 
as constituições brasileira e argentina trazem formas políticas plurais com o empoderamento da participação popular na vida política em busca de reconstrução institucional da democracia, com a previsão de mecanismos de pluralismos políticos, com participação popular e pluripartidarismo. Esse processo tem continuidade com as constituições colombiana e venezuelana, sendo marcado por demandas sociais imediatas, como acesso aos serviços públicos mínimos e repartição das receitas públicas advindas da exploração de recursos minerais. O móvel político ativador desses processos passa a ser a igualdade pública e a participação democrática nos processos decisórios.

Na próxima década, o processo de incremento da participação popular na vida política continua com as Constituições da Bolívia e do Equador, agora avançando para a afirmação de novas subjetividades e construção de uma identidade legitimamente latino-americana, por meio do resgate de conceitos culturais e jurídicos autóctones. Isso resultou na consagração, na Constituição do Equador, de conceitos como "sumak kawsay" e "pachamama"(ZAFFARONI, 2012, pp.55 e 15 )’ Esses Estados se refundam como estados plurinacionais.

Toda a construção do estado nacional moderno dependeu da elaboração de uma identidade nacional, o que, na prática, levava à imposição de valores comuns que deveriam ser aceitos (à força, ou introjetados gradativamente) e compartilhados pelos diversos grupos étnicos que, pois, reconheceriam o rei (e o estado, posteriormente, no constitucionalismo). A construção do estado nacional, por si só, já configura uma política de dominação e império de uma etnia hegemônica sobre as demais, o que se reproduziria, mais tarde, entre os estados nacionais europeus e suas colônias(MAGALHAES, 2012).

Desde suas origens o estado nacional maculou-se na dominação e império, violentando minorias étnicas, que seriam encobertas, ou silenciadas, por uma nacionalidade, uma identidade "nacional", construída artificial e artificiosamente, através de mais políticas espúrias de marginalização. Como afirma José Luiz Quadros de Magalhães, "Assim, na Espanha, o rei castelhano agora era espanhol, e todos os grupos internos também deveriam se sentir espanhóis, reconhecendo assim a autoridade do soberano"(2012, p.29). A construção da identidade nacional é apenas um dispositivo para mascarar (encobrir, ocultar e permitir esquecer) o domínio étnico, tornando-o natural, facilitando sua aceitação.

O discurso de hegemonização é uma constante na modernidade. Primeiro como construção da identidade nacional, depois no processo de invasão das Américas, 
o discurso da missão civilizatória e, agora, na contemporaneidade, como intervenção humanitária e de direitos humanos. Há a permanente reinvenção do discurso de justificação e legitimação do império e dominação de etnias, com suas máscaras novas mas sempre com as velhas pretensões de verdades imutáveis e universais.

A construção artificial, o desenvolvimento violento e genocida e a manutenção imperial do estado nacional, por manifestar uma indisfarçável politica de império e dominação de povos majoritárias sobre minoritários, origina o estado que constantemente marginaliza, exclui ou extermina o diferente. $\mathrm{O}$ sujeito que não se enquadra nos estreitos limites da identidade nacional- o homem branco, varão, cristão e pequeno burguês.

A importação do modelo do estado nacional pela América Latina teve efeitos perniciosos mais exacerbados do que em seu continente de origem, a Europa. Na América Latina os estados se organizaram por e para uma parcela minoritária da população, que representava, igualmente, uma minoria étnica -descendentes de europeus. As práticas democráticas em que se assentam os estados nacionais foram direcionadas para não construir consensos, mas para abreviar ou mutilar o diálogo e perpetuar oligarquias: democracia é a deliberação da maioria e a maioria é a maioria numérica étnica que, pois, continuará no poder, ou, ainda, maioria é a maioria econômica, que tem condições de manipular a maioria numérica. Enfím, não há democracia, mas uma autocracia induzida pela intolerância ao diferente.

A fim de superar a intolerância do estado nacional, denunciar a sua postura uniformizadora e normalizadora que descaracteriza os seres humanos, de carne e osso, nome e sobrenome, transformando-os em meros componentes reprodutores de um sistema econômico hegemônico, organiza-se o estado plurinacional no cenário político, jurídico e cultural mundial, sobretudo com as experiências de Bolívia e Equador. Em tais experiências, mais que criticar a posição colonial ainda persistente, ativa-se a participação popular no sentido de reconhecer a diferença, a complexidade das formas sociais dentro de um país, a coexistência de culturas diferentes e, no que nos interessa direta e especialmente, ordenamentos jurídicos diferentes, materializados na coexistência (horizontal) de direitos consuetudinários e direito estatal oficial.(TARREGA e GONÇALVES, 2011)

A pluralidade de formas culturais e jurídicas existentes em um mesmo país, e o seu reconhecer pelo povo, impõe acolher a diversidade, com a adição de novos sujeitos sociais no contexto político, cria o modelo de "Estado Plurinacional"1. As novas Cartas rompem com o mito da identidade nacional- tradição da modernidade de 
associar uma só nação enquanto realidade sociocultural forjada ideologicamente, com um só estado, realidade político-territorial. Criam o estado plurinacional a coexistência democrática de várias nações ou nacionalidades, marcadas por territorialidades múltiplas (não território) num mesmo marco geográfico de um estado.

O modelo de estado plurinacional afirma as semelhanças e diferenças do povo -plurinacional, em um espaço -estado, democraticamente partilhado -pelo respeito à diferença, através da participação dos sujeitos coletivos plurinacionais e pluriculturais no processo constituinte. O referido modelo afirma seu caráter de pluralidade dispensando tratamentos normativos específicos de cada sociedade, ou cada nacionalidade: o que está relacionado aos direitos das nacionalidades deve ser resolvido sob uma perspectiva de interculturalidade.

A diferença deve não só ser reconhecida, mas passa a configurar, em si mesma, um direito. O indivíduo, ou o grupo social, só afirma sua identidade se a sociedade reconhece a diferença, de molde a termos o direito à diferença como um integrante do cluster de direitos da personalidade. $\mathrm{O}$ estado plurinacional "garante a existência de formas de constituição da família e da economia segundo os valores tradicionais de diversos grupos sociais (étnicos e culturais) existentes." (MAGALHÃES, 2012, p.29) O pluralismo, jurídico e cultural, não só é reconhecido, como passa a integrar o centro de ordenação da vida de uma sociedade.

\section{PLURALISMO JURÍDICO, SUBJETIVIDADES E SUJEITOS DE DIREITOS.}

A concepção das subjetividades ganha novos contornos no Estado plurinacional, superando a colonialidade normativa. Para dar suporte à efetivação dos direitos desses novos sujeitos políticos exigem-se referências teóricas jurídicas. Os direitos de personalidade trazidos da privatística ocidental, categorias construídas para atender os avanços do liberalismo econômico pós Revolução Francesa, são insuficientes para dar concreção a esses novos direitos. E a prática da jurisdição ainda se funda em construções teóricas. Deixar o direito civil tradicional resolver as novas questões é impedir os avanços políticos propostos.

\footnotetext{
${ }^{1}$ A Constituição Equatoriana de 2008, no artigo $1^{\circ}$ define o Estado Plurinacional.
} 
Pensar sobre conceitos que abriguem as novas subjetividades impõe resgatar historicamente a ideia de sujeito de direito.

A construção da categoria sujeito-pessoa dá-se ao longo da história, mas a modernidade traz a fundação do indivíduo e o coloca como núcleo central das questões jurídicas. Os primados da Revolução Francesa referendam essa estrutura. Com a consagração do princípio da igualdade e a imposição da liberdade e da fraternidade, o sujeito de direito torna-se o centro da normatividade- uma preocupação concreta do direito. É esse direito engendrado no estado nacional, no seio do liberalismo que faz aflorar a noção de sujeito de direito-pessoa-indivíduo da normatividade colonial.

O direito anterior ao direito unificado pelo estado nacional abriga noções de justiça comum, não individual. Antes da unificação estatal, mesmo sem a equânime distribuição de justiça, o status, o comunitário determina os particularismos da sujeição da pessoa ao direito. O sujeito pertence a um grupo, a uma comunidade e a partir da situação existencial nele, sujeita-se às suas normas. O coletivo e a certeza do pertencimento obstaculizam e tornam o direito subjetivo individual fora de questão. $\mathrm{O}$ que a pessoa recebe na jurisdição é por justiça, não por direito individual. Acrescente-se a isso, a inocorrência de uma perspectiva jurídica antropocêntrica que permita centralizar o indivíduo pessoa - sujeito de direito- no campo do conhecimento jurídico e da normatividade.

As pessoas têm direitos por justiça, direitos personalíssimos inclusive, mas a pessoa homem sujeito indivíduo não ocupa posição jurídica nuclear. É a dimensão justiça, que se busca realizar, dentro de um contexto coletivo. Segundo Mário Reis Marques (2012, p.234) o que faz transparecer a não unificação do sujeito de direito nesse período da história é a multiplicidade subjetiva. “Assim, ao invés de tratar todos de forma idêntica, a ordem jurídica distingue, diferenciando as regras do agir jurídico de acordo com o status dos diversos sujeitos jurídicos." (2012,p.234).

O estado nacional muda de multiplicidade subjetiva, que hoje se tenta resgatar de maneira mais equânime. O direito nacional generaliza, uniformiza normas para um sujeito padrão. A norma é universal e geral, contemplando sujeitos igualmente gerais e universais. A universalização do direito para todos os sujeitos reclama a configuração desse sujeito que se enquadra no tipo do indivíduo igual a todos (TARREGA, 2013).

O sujeito aparece inicialmente, no plano teórico da racionalidade jusnaturalista, quando se afirmam os direitos inatos do homem. Surge aí a noção de 
direito individual e o sujeito floresce no âmago das especulações do direito no estado nacional. É também no âmbito deste modo de pensar que o sujeito de direito passa a ser identificado como pessoa. É a semente da ideia de direito enquanto atributo de sujeitos. $^{2}$ A racionalidade moderna colonial subjuga o homem, aniquilando diversidades culturais.

No estado nacional o sujeito de direito - indivíduo é o vértice da questão jurídica. "É este um período marcado por uma clara acentuação da tendência para a «subjetivação dos direitos e para o reforço dos direitos individuais face ao Estado».(MARQUES, 2010, p.101) O espírito burguês manifesta-se por meio de um individualismo anticorporativo que postula o cidadão como célula autônoma da humanidade, como centro de imputação de direitos subjetivos" (MARQUES, 2010, p.101). É nesse contexto que o homem passa a condição de sujeito de direito, que se determina que a personalidade é igual para todos os cidadãos e que a capacidade jurídica, já afastada dos estamentos, deve ser a medida da personalidade. O homempessoa será o sujeito de direito dos códigos e dos direitos nacionais- da normatividade colonial.

Nesse contexto os menos capacitados na perspectiva econômica, e isso na América Latina são os povos originários, os escravizados, as mulheres, as crianças, são as excepcionalidades, desprezadas pelo direito. "O sujeito jurídico pressuposto é o homem adulto proprietário". (MARQUES, 2010, p.104). É o sujeito que vai promover a circulação de riquezas numa perspectiva liberal. É esse sujeito de direitoo homem dotado de personalidade cuja capacidade conferir-lhe-á as dimensões- que vai ser o objetivo último da normatividade, no estado nacional. O homem dotado de capacidade econômica plena e de autodeterminação, numa perspectiva liberal.

Paolo Grossi afirma como ponto essencial que distingue a modernidade jurídica é a estatalidade do direito. (2006, p.53) . "O velho pluralismo jurídico é em um golpe eliminado e o absolutismo jurídico toma sempre mais espaço na civilização do máximo liberalismo econômico". (2006, p.53) .

\footnotetext{
${ }^{2}$ A ponta desse fio condutor está na sociedade estamental, em que o homem conformado ao seu status, balisado por uma série de condicionantes que o determinam, é considerado um sujeito. Ainda não como elemento central de um sistema, mas já sujeito. Sujeito que se configura pelas suas condições de existência. E nelas tem definida a sua capacidade ( a capacidade de cada sujeito), capacidade mesma que será, posteriormente, o aspecto central da jurisdição na era dos códigos. (é a semente). (TARREGA, 2012)
} 
Um novo estado de direito fundado no pluralismo, para vencer as injustiças consagradas pela redutiva igualação e elitização de direitos e refigurar esse padrão de sujeito de direito liberal da normatividade colonial, sob novas perspectivas teóricas, necessita da introdução de outros elementos para a identificação dos sujeitos, por meio instrumentos de identificação abertos.

Os instrumentos devem acolher a diversidade, no contexto histórico próprio. A busca pelo sujeito de direito há de dar por ações de identificação em que incorporem valores e em que irrompam capacidades e responsabilidades. A procura da identificação é direcionada ao sujeito dotado de alguma capacidade mas também muito mais do que isso. Exige-se, nesta procura, a inclusão de valores que não se reduzam à capacidade econômica. Que deem plenitude ao homem. Como diz Ricoeur: "Examinando as formas mais fundamentais da pergunta quem? Somos obrigados a conferir sentido plenos a noção de sujeito capaz" (2008, p. 21).

É necessário ampliar a noção de capacidade para incluir todo o possível respeito. A capacidade há de ser verificada à partir da sua diversidade cultural e humana, o que gera o seu reconhecimento como sujeito de direito e o respeito à sua humanidade.

Mas isso agregado a noção de capacidade ainda é insuficiente. À capacidade designa também atribuição. A identificação de um agir humano significa atribuir a alguém uma ação, e aqui se encontra o possível diferencial da perspectiva jurídica liberal. Porque nessa seara se integram valores alheios à universalização do modelo codificado. (TARREGA, 2012) É preciso identificar as possíveis e múltiplas capacidades e o leque de atribuições, para encontrar no contexto histórico da juridicidade os sujeitos e os seus direitos.

Mister se faz o reconhecimento do sujeito num processo histórico e cultural. Primeiro nas relações interpessoais, em que aflora a ética da alteridade, que no plano do direito há de ser emancipatória.

$\mathrm{Na}$ proposta ricoeuriana, momento em que um sujeito age, ele cria uma polaridade, cria uma relação “eu-tu'. Explica Martin Buber que a relação com o tu é imediata. "Entre o Eu e o Tu não se interpõe nenhum jogo de conceitos, nenhum esquema, nenhuma fantasia; e a própria memória se transforma no momento em que passa dos detalhes à totalidade.(2009, p.49). Nessa interpessoalidade "eu-tu" emergem sujeitos de direito- quando o eu se vê no tu, quando acontece o que Ricoeur chama de "eu mesmo como outro". Essa relação "eu-tu" deve vir inserida em um contexto de veracidade, de sinceridade. Eu só posso me ver no outro se acreditar que 
o outro é sincero. É a ética que o pluralismo vai resgatar momento adiante.

Mas a busca do sujeito de direito na perspectiva do pluralismo jurídico requer mais do que o seu observar na relação interpessoal. Exige-se uma perspectiva contextual coletiva e comunitária. No discurso, no diálogo, aparece sempre um terceiro, que é o referente ou a materialização do eu mesmo como o outro, distendendo-se para o passado, presente e futuro. Revelam-se experiências e expectativas que ampliam a relação para a comunidade, para o comunitário, para o político.

O sujeito capaz na espera pública é o sujeito de direito, sujeito político. Um sujeito com responsabilidades públicas, políticas. Assim, o jurídico é também um problema político. “ O poder político, através de todos os níveis de poder considerados, apresenta-se em continuidade como o poder por meio da qual caracterizamos o homem capaz" (RICOEUR, 2008, p.29).

A negação da responsabilidade política do sujeito capaz é fruto da resposta do estado nacional ao liberalismo econômico. O direito nacional moderno, com a normatividade colonial, isolou o sujeito de direito do contexto da esfera pública e recolocou em um espaço de contrato fundacional e apolítico. É como se no momento em que pactua, o homem se isolasse de toda comunidade para decidir o futuro dela mesma.(MARQUES, 2013) Numa relação paradoxal, um sujeito de direito dado pelo jogo comunitário se torna sujeito de direito apartado da sociedade. E nesse sentido em Hobbes o sujeito que pactua em ceder parte de sua liberdade para o estado é um sujeito que entrou no jogo contratual plenamente capacitado como sujeito de direito. (RICOEUR, 2008, p.31)

A ideia de sujeito capaz, ou seja- o sujeito dotado de direito e de deveres, é insuficiente para sustentar os pluralismos, o sujeito político, coletivo ou mesmo as novas subjetividades emergentes. Um sujeito de direito há que ser colhido de um contexto público, vez que está inserido em um contexto político e comunitário. E responde de acordo com esses contextos.

Paul Ricoeur (2008) afirma que um sujeito de direito é aquele que está mediado continuamente por formas interpessoais de alteridade e formas institucionais de associação. Esse sujeito pode responder às formas de pluralismo jurídico e político. A realização do pluralismo jurídico depende do sujeito no seu espaço social e político. A noção de sujeito de direito, a relação dever e responsabilidade deve ser posta em espaço público.

O direito moderno e a normatividade colonial usou da noção de sujeito de 
direito capaz para construir uma justiça excessivamente universalista, para promover a hierarquização, a dominação dos sujeitos. Uma proposta para alcançar o sujeito plural é superar noção de sujeito de direito advinda do sujeito capaz liberal, para a noção de homem capaz( no pensamento de Ricoeur). A noção de l'homme capable é a linha mestra do pensamento ricoeuriano sobre o tema, e impõe considerar as vulnerabilidades, que é o diferencial das novas subjetividades nas Constituições latino-americanas das três últimas décadas.

$\mathrm{Na}$ ideia de homem capaz ricoeuriana, a capacidade humana está além dos parâmetros postos na legislação moderna, referentes à possiblidade de apropriação de bens e autodeterminação de sua disposição. A capacidade para Ricoeur (2008) estabelece o link entre o ação e o sofrimento humano. As capacidades se entrelaçam com as vulnerabilidades e a pessoa capaz é aquela que está apta a realizar e ser responsável. Nesta proposta conceitual pode-se pensar os sujeitos de direitos nos contextos históricos e coletivos plurais, numa perspectiva emancipatória.

\section{PLURALISMO JURÍDICO PARA EMANCIPAÇÃO DOS SUJEITOS.}

O pluralismo jurídico na proposta do estado plurinacional pressupõe um direito para a emancipação dos sujeitos. Em uma concepção instituída sobretudo pelos Estados refundados, comunicando-se com as dimensões do pluralismo sociológico, econômico e político, nega-se o protagonismo estatal exclusivo da produção normativa regulamentadora de uma sociedade. Como anuncia Wolkmer (2001, p.183), propõe uma visão "antidogmática e interdisciplinar que advoga a supremacia de fundamentos sociológicos sobre critérios tecno-formais" Para o pluralismos, além do Estado, existem corpos sociais intermediários com capacidade de produzir ordenamentos jurídicos autônomos, ou seja, produzem prescrições conformativas do comportamento dos sujeitos de direito componentes de determinado segmento social. O pluralismo jurídico (WOLKMER, 2012, p.238) devolve o sujeito ao espaço político porque consiste na multiplicidade de práticas existentes em um mesmo espaço sócio-político, caracterizadas por interações de consensos e dissensos, oficiais ou não, tendo fundamento ontológico em necessidades existenciais, materiais e culturais ( TARREGA E GONÇALVES, 2015).

Oscar Correas (1994), entende que em toda sociedade moderna coexistem distintos sistemas normativos, mas que ditos sistemas não são necessariamente jurídicos; o pluralismo seria, portanto, a coexistência de sistemas normativos diversos que pretendem validez em um mesmo território Correas entende que a relação dos 
diferentes sistemas normativos entre si pode se operar de maneira alternativa ou subversiva. A alternatividade ocorre quando o sistema oficial hegemônico convive de maneira alternativa com os demais. Isso se dá sobremaneira quando há plurinacionalidades, e subjetividades coletivas, como o caso de comunidades indígenas na América latina ou dos ciganos da Espanha.

Por fim, importa consignar a advertência de German Palacio (1989, pp. 51 a 70), de que a crise do monismo jurídico, pela sua insuficiência ao tratar de maneira satisfatória os conflitos multifacetados que ocorrem no seio social, precipitaram a emergência do pluralismo jurídico, de maneira que o direito do estado é substituído ou complementado por múltiplas instituições. Palacio ressalta a importância do direito surgido do povo, como signo tradutor das lutas sociais e práticas inovadoras e insurgentes, o que referenda a ideia de que o novo sujeito de direito há de ser encontrado no espaço comunitário e político.

Já refletindo na libertação dos sujeitos com relação à ordem posta, Luiz Fernando Coelho (1981) alerta para a necessidade da transposição da concepção jurídica ontológica da unicidade e estabilidade, para um nível dinâmico da ontologia do ser social. O ser social é plural, não sendo possível ao estado abordar toda a fenomenologia social da sociedade. Seria necessário conferir um novo fundamento ao pluralismo jurídico, e aí reside sua principal contribuição para o pluralismo, de molde a articular o pluralismo jurídico com movimentos sociais insurgentes e desafiadores da ordem oficial, sob a perspectiva de promover emancipação dos marginalizados pela ordem.

\section{LEGITIMAÇÃO E EMANCIPAÇÃO DOS SUJETOS NO PLURALISMO JURÍDICO.}

Antônio Carlos Wolkmer (2012, p.204) elabora de maneira sistemática uma teoria do pluralismo jurídico, apresentando como requisitos a legitimidade de novos sujeitos sociais, a fundamentação do pluralismo na justa satisfação de necessidades humanas, a democratização e descentralização do espaço político, a defesa de uma ética da alteridade e a consolidação de uma racionalidade emancipatória.

No que diz respeito à legitimação dos sujeitos, o pluralismo no pensamento se Wolkmer, parte do pressuposto que os novos movimentos sociais são geradores de produção jurídica. Propõe-se a superação do sujeito atomizado da tradição liberal racionalista, para que um novo sujeito cognoscente surja a partir do sujeito coletivo, 
que participa e modifica o processo social- portanto sujeito comunitário e político. Dessa maneira, a realidade social, objeto de conhecimento daquele sujeito, é estudada agora do ponto de vista de um sujeito coletivo que agrega outros sujeitos outrora inertes e dominados e que, então, comunitariamente, promove sua participação e emancipação. Assim, o pobre, o despossuído, o descamisado, os marginalizados de todo gênero, que antes percebiam a realidade de maneira individualista, e se prostravam impotentes diante dela, agora, sob o manto do coletivo social, sujeito social, passa a encarar a realidade como um objeto passível de transformação, de forma a promover sua própria inclusão.

Os sujeitos coletivos passam a protagonizar reivindicações e demandas e esses sujeitos coletivos identificam-se com um conceito de povo revisitado. O povo enquanto sujeito histórico coletivo, é representado nas lides da América Latina pela população oprimida de camponeses, trabalhadores, indígenas, negros, mulheres etc. Os novos sujeitos coletivos de direito compõem uma realidade sociológica que justifica seu enquadramento na esfera de relevância jurídica. A justificação é aferida pela necessidade, o que nos remete a Ricoeur e à relação capacidade/ vulnerabilidade.

A justa satisfação de necessidades humanas (como um segundo pressuposto wolkmeriano) os novos sujeitos coletivos, traduzidos dos movimentos sociais, afirmam-se e justificam-se por um sistema de necessidades. O pluralismo pressupõe que o direito oficial hegemônico negou a parcelas da coletividade condições para a construção de seus projetos de vida. A exclusão é justamente a negação das necessidades humanas fundamentais aos grupos marginalizados. Necessidades humanas fundamentais, no ministério de Agnes Heller (1990), compreendem o conjunto de necessidades de vida, de subsistência e culturais. Uma necessidade é reconhecida como legítima se sua satisfação não inclui a utilização de outra pessoa como meio. (1990, p.216 a 219)

É também pressuposto do pluralismo jurídico a implementação de uma política democrática que crie um espaço comunitário descentralizado e participativo. Com efeito, só se pode falar de um pluralismo com viés emancipatório se tivermos um espaço político que viabilize a autodeterminação e auto-organização das estruturas sociais. Apenas nesse contexto é que se pode conceber um ambiente para se conscientizar da condição de excluído e um debate acerca de sua superação.

O que se propõe é o reordenamento do espaço público para que se resgaste os conceitos de comunidades, políticas democráticas de base e participação e controle popular. A percepção de comunidade implica em um grupo social com interesses 
comuns e identidade própria dentro de um espaço geográfico ou uma territorialidade específica e que pressuponha uma consciência de reciprocidades valorativas. Pode-se dizer que os elementos integrantes de uma comunidade experimentam a consciência de que construíram práticas comuns e singulares, que lhes apartam dos demais grupos sociais.

A construção de uma sociedade democrática alicerçada nas necessidades da comunidade dependem de uma cidadania consciente e atuante e, também, de uma decisão dentro do direito oficial de descentralização político-administrativa que implique redistribuição de recursos políticos. No que tange à cidadania - não se cogita de uma cidadania mediada ou de segunda categoria (GARAPON,2001), presa a instituições mediadoras (voto delegativo, delegação judicial de necessidades fundamentais e políticas assistencialistas), mas sim, de sujeitos políticos ou seja do sujeito de direito no contexto comunitário- atuando diretamente junto às instâncias oficiais de poder.

O pluralismo jurídico pressupõe uma ética da alteridade que o legitima. Anota Wolkmer que a crise ética contemporânea funda-se em perda de identidade cultural, em desumanização das relações sócio-políticas, "no individualismo irracionalista e egoísta, na ausência de padrões democráticos e comunitários, senão ainda na constante ameaça de destruição da humanidade e de seu meio-ambiente" (2001, p.261). Dessa maneira há um impasse na construção de conceitos éticos basilares como "vida boa", "bem comum", "virtude" e "justiça".

Nesse particular, a busca por valores éticos, ou de sua correta interpretação, na legitimação de ações políticas, ou de sistemas políticos por inteiro, vai se resolver também na perspectiva dos sujeitos, ou do eu. Quando da interação em que o "eu" se vê no "tu, quando acontece o que Ricoeur chama de "eu mesmo como outro". No “Outramente”(RICOEUR, 2000). Quando a relação “eu-tu” é posta no contexto histórico desnudado das ideologias. Quando se traduz na crença da sinceridade. (Eu só posso me ver no outro se acreditar que o outro é sincero.) Na justiça como lealdade ampliada (RORTY, 2010).

O sujeito posto no espaço político e comunitário conhece e interpreta a realidade e responde a ela por meio de uma racionalidade emancipatória. Uma nova racionalidade originária da vida concreta, que traduz a identidade cultural do sujeito, tomada como afirmação de sua liberdade, emancipação e autodeterminação. Liberta-o do estado de marginalização. $O$ novo sujeito capaz- tomado nas relações interpessoais, coletivas e comunitárias, portanto comunitária e politicamente 
responsável, percebe a realidade coletiva como sua própria realidade, e não a partir da perspectiva padronizada de outros sujeitos-referência- proposta monista hegemônica epistemológica.

Wolkmer fala de um sujeito emancipado a partir do especial modo como os esses sujeitos percebem a realidade. Primeiramente, impõe-se que os membros da sociedade de conhecimento tenham a capacidade de se apropriar dos modelos de conhecimento disponíveis e gerados em qualquer parte. Em segundo, os membros da sociedade podem aproveitar da melhor maneira os conhecimentos universais produzidos historicamente, incluindo os científicos e tecnológicos, mas, também os conhecimentos tradicionais, com igual importância. Em terceiro, os próprios membros da sociedade de conhecimento possam gerar, eles mesmos, conhecimentos para melhor enfrentar seus problemas.(OLIVÉ, 1999, p.20). .

A racionalidade emancipatória inaugura uma percepção da realidade que considera as particularidades dos sujeitos no processo de conhecimento, de maneira a consagrar, então, múltiplos processos de conhecimento (pluralidade epistemológica) e múltiplos tipos de conhecimento (pluralismo cultural), o que redunda na emancipação do sujeito, que pode perceber a realidade a sua maneira, com subsídios nos conhecimentos científicos amplamente divulgados e, também, com espeque em conhecimentos construídos a partir de uma identidade cultural. A racionalidade emancipatória é comunitária.

\section{CONCLUSÕES}

O pluralismo jurídico está ínsito na proposta do estado plurinacional, nos processos democráticos contemporâneos. Por sua vez, este pluralismo jurídico contemporâneo pressupõe um direito para a emancipação dos sujeitos. Um direito que supere a normatividade colonial hegemônica do direito oficial. Revela novas subjetividades, mas deixa em aberto a busca por tantos outros sujeitos que na vida política e comunitária se fizerem sujeitos de direitos.

E assim se dá, tendo em vista que estados plurinacionais contemporâneos instituem como mobilizadores dos processos democráticos maior participação popular no sentido de reconhecer diferenças, complexidades sociais, coexistência multiculturais e ordenamentos jurídicos diversos, que se materializam na realidade social em um estado plural de direitos.

A concreção deste estado exige o reconhecimento de subjetividades outras, por 
formas diferenciadas de identificação. Estabelece-se assim um processo aberto de buscas.

Um sujeito capaz, no mais amplo sentido de resgate das subjetividades para realizar um estado plural de direitos , é aquele cujos deveres e atribuições, extrapolam o plano da propriedade e da circulação das riquezas, como se verifica na teoria tradicional do direito civil moderno, como resposta ao liberalismo econômico. As imputações para os seus atos e para as suas atribuições devem se dar nos espaços público, comunitário e político, que é o mobilizador dos novos processos democráticos. O sujeito posto no espaço político e comunitário conhece e interpreta a realidade e responde a ela por meio de uma racionalidade emancipatória. Realidade que conhece e estende aos outros sujeitos da comunidade, num caráter de empoderamento.

O pluralismo jurídico enquanto proposta, fomenta o empoderamento dos novos sujeitos. Mas a sua concretização depende de muitos outros fatores

O que se tem observado nas democracias contemporâneas do Sul é que, embora se reconheçam avanços e se ampliem as noções de sujeito de direito, a prática jurídica em muitos países reproduz a ordem político-jurídica fundada pelo constitucionalismo de direitos do século XVIII, consagrando a assimetria de poder e impedindo ou dificultando a manifestação dos não iguais. Os sistemas de monitoramento dos direitos dos sujeitos diversificados, não funcionam porque atuam apenas em prol da igualdade e desprezando a diversidade. A ordem jurídica está presa aos primados da liberdade, da igualdade, da fraternidade, nos moldes do direito privado moderno. 


\section{REFERÊNCIAS}

BUBER, Martin. Eu e tu. Tradução Newton Aquiles von Zuben, São Paulo: Centauro. 2009.

COELHO, Luiz Fernando. Lógica jurídica e interpretação das leis. 2 ed. Rio de Janeiro: Forense, 1981.

CORREAS, Oscar. Introducciíon a la sociologia juridica. México: Ediciones Coyoacán, 1994, CUCCI, Giovani. O perdão segundo Paul Ricoeur. In. La Cilvittá Cattolica. Tradução Maria Alves Muller. 2009. p.145-153.

GARCIA, José Luís. Rumos a criação desenhada dos seres humanos. IN Revista estudos de sociologia. Recife. Editora da UFPE, 2006. Disponível em: $<<$ http://www.scientiaestudia.org.br/pt2007/rumo\%20a\%20criacao.pdf acessado em 03/08/2015.

GARAPON. Antoine. O juiz e a democracia. O guardião das promessas. Rio de Janeiro: Revan, 2001.

GROSSI, Paolo. Primeira lição sobre direito. Tradução Ricardo Marcelo Fonseca. Rio de Janeiro: Forense, 2006.

HELLER, Agnes. Más allá de la Justicia. Barcelona: Crítica, 1990 .

HUSSERL, E. Meditações cartesianas: introdução à fenomenologia. Tradução Maria Gorete Lopes e Souza. Porto: Rés, 2001.

KAPLAN, D. M. Reading Ricoeur. Albany, New York Press, 2008.

MAGALHÃES. José Luiz Quadros de. Estado Plurinacional e Direito Internacional. Editora Juruá: Curitiba, 2012.

MARQUES, M. R. Um olhar sobre a construção do "sujeito de direito" Stvdia iuridica, 96 . Boletim da Faculdade de Direito. Universidade de Coimbra. Coimbra.

O direito como uma gestão de urgência ou uma normatividade com um tempo próprio. Stvdia iuridica, 90 . Boletim da Faculdade de Direito. Universidade de Coimbra. Coimbra.

MORIN, E. A noção de sujeito. 1999, in mimeo. 
OLIVÉ, León. Multiculturalismo y pluralismo. México: Paidós, 1999. .Interculturalismo y justicia social. México: UNAM, 2004.

PALACIO, Germán. Servicios legales y relaciones capitalistas: un ensaysobre los servicios jurídicos popiulares y la práctica legal crítica. El otro derecho, Bogotá, n. 3, p. 51-70. jul/1989.

PELLAUER, David. Compreender Ricoeur. Tradução Marcus Penchel. Petrópolis. Editora Vozes 2009.

RICOEUR, Paul: O Justo. Tradução Ivoneti Beneditti. Ed. Martins Fontes São Paulo 2008.

O justo ou a essência de Justiça. Lisboa, Instituto Piaget,1995.

Existência e hermenêutica. In BLEICHER, Hermenêutica Contemporânea. Lisboa - Rio de Janeiro, 1992, p.327/352.

Outramente. Trad. Pergentino Stefano Pivatto; Petrópolis: Vozes 1999.

1997.

Memória, História e esquecimento. Campinas, Ed.Unicamp.

RORTY, Richard. Justiça como lealdade ampliada. Tradução: Paulo Ghiraldelli Jr. Disponível em 《<http://portal.filosofia.pro.br/arquivo-rorty.html $>$ Acesso em: 28/08/2015.

ROSILLO, Alejandro. Derechos humanos, pensamento crítico y pluralismo jurídico. Universidad Autonoma de San Luis Potosi, San Luis Potosi, 2008.

SANTOS, Boaventura de Souza. Poderá o Direito Ser Emancipatório? Revista Crítica de Ciências Sociais. n. 65, Maio 2003, pp. 3-76.

SANTOS, Boaventura de Souza. Uma concepção multicultural. Revista Lua Nova, 1997, n.39, pp. 105-124.

STEIN, Ernildo. Diferença e metafísica: ensaios sobre a desconstrução. Porto Alegre: Edipurcs, 2000.

TARREGA, Maria Cristina V. B. O sujeito público para além do sujeito privado no Constitucionalismo democrático latino-americano. Instituto Tueri. Chile, 2012. 
TARREGA, Maria Cristina V. B.,CORREIA, Pedro Henrique Guimarães. A construção narrativa da ideia de sujeito de direito e justiça. Revista da Faculdade de Direito da UFG, v.35, n.2, 2011, pp.88-105, disponível em https://www.revistas.ufg.br/index.php?journal=revfd\&page=issue\&op=view\&path\%5 $\mathrm{B} \% 5 \mathrm{D}=1225 \&$ path\%5B\%5D=showToc. Acesso em 10.12.2015.

TARREGA, Maria Cristina V.B., GONÇALVES, Daniel Diniz. Pluralismo epistemológico no direito e nas universidades.Revista da Faculdade de Direito da $U F G, \quad$ v.39, n.1, 2015, pp. 173-191, disponível em https://www.revistas.ufg.br/index.php?journal=revfd\&page=issue\&op=view\&path\%5

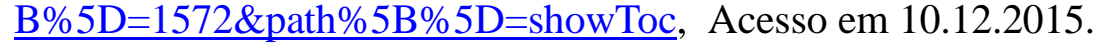

WOLKMER, Antônio Carlos. Pluralismo e crítica do constitucionalismo na América Latina. In: Anais do IX Simpósio Nacional de Direito Constitucional. Curitiba: Academia Brasileira de Direito Constitucional, 2010. p. 143-155.

WOLKMER, Antônio Carlos. Pluralismo Jurídico: Fundamentos de uma nova cultura no Direito. Editora Alfa-Ômega: São Paulo, 2001.

WOLKMER, Antônio Carlos. Introdução ao Pensamento Jurídico Crítico. 8 ed. Saraiva: 2012.

ZAFFARONI, Eugénio Raul. La Pachamama y el Humano. Buenos Aires: Ediciones Colihue, 2012. 